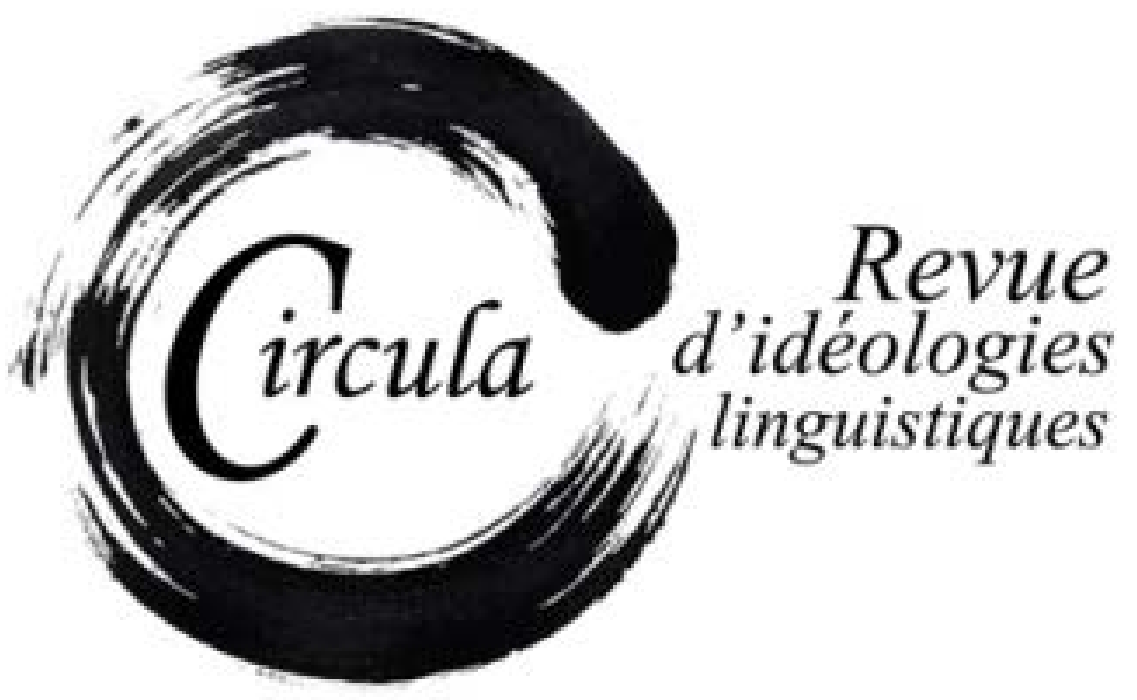

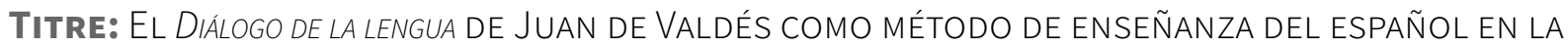
ITALIA RENACENTISTA

Auteur(s): Verónica Pantoja Gallego, Universidad de Granada

Revue: Circula, numÉRo 8 - IDEOlogías en obras sobre LA LENGUA ESPAÑola (SS. XV-XX)

PAGES: $30-51$

ISSN: 2369-6761

Directeurs: : Francisco Escudero Paniagua, Carlos Villanueva García, Carmen Quijada Van DEN Berghe, José Jesús Gómez Asencio

URI: HTTP://HDL.HANDLE.NET/11143/15550

DOI: HTTPS://DOI.ORG/10.17118/11143/15550 


\section{El Diálogo de la lengua de Juan de Valdés como método de enseñanza del español en la Italia renacentista}

Verónica Pantoja Gallego, Universidad de Granada verohispanica@correo.ugr.es

Resumen: Vemos el Diálogo de la lengua como método de enseñanza del español para extranjeros. Este propósito didáctico se aprecia en el empleo por Juan de Valdés de varios aspectos y recursos para la enseñanza del español que se siguen utilizando en pleno siglo XXI: espontaneidad, naturalidad en el diálogo, estrategias conversacionales, humor y aspectos pragmáticos y culturales. A través de sus explicaciones sobre la lengua consigue ofrecer un rico testimonio de la situación de la lengua castellana en el siglo XVI y, al mismo tiempo, podríamos decir que se convierte en iniciador de un camino que nos llevará hasta los actuales métodos de enseñanza del español como lengua extranjera.

Palabras clave: pragmática; enseñanza-aprendizaje; diálogo; oralidad; cultura

Abstract: We see the Diálogo de la lengua as a method of teaching Spanish as a foreign language. This didactic intention is appreciated in the use by Juan de Valdés of different aspects and language resources for teaching Spanish, which are still used in the $21^{\text {st }}$ century: spontaneity, natural dialogue, conversational strategies, humour and pragmatic and cultural aspects. He provides valuable evidence of the Castilian language during the $16^{\text {th }}$ century through different linguistic explanations. At the same time, he became the starter of a path which leads us to the current methods of teaching Spanish as a foreign language.

Keywords: pragmatics; teaching-learning; dialogue; orality; culture 


\section{Introducción}

El presente trabajo tiene como objeto de estudio la relación existente entre las recomendaciones didácticas de Juan de Valdés ${ }^{1}$ presentes en el Diálogo de la lengua, obra lingüística escrita hacia 1535, y los recursos empleados en los métodos actuales de enseñanza del español como lengua extranjera. En el Diálogo, Valdés comparte apacibles conversaciones con Marcio, Coriolano (dos amigos italianos) y Torres o Pacheco, según la edición (amigo español); la temática de la reunión gira en torno a cuestiones sobre la lengua castellana -origen de la lengua castellana, gramática, pronunciación, ortografía, léxico, estilo, obras literarias y refranes - y tiene lugar en la sobremesa. La conversación viene motivada por unas cartas escritas, recurso ficcional propio del Renacimiento, de las que surgirán gran parte de las preguntas que sus amigos le propondrán a Valdés.

Ante esta situación, Valdés se convertirá en guía y maestro y ayudará a solucionar las cuestiones lingüísticas que le plantea su círculo de amigos napolitanos. Para ello se servirá de la pragmática, la oralidad y el empleo del diálogo, forma de organización del discurso típica del Renacimiento que, junto a la espontaneidad y las estrategias conversacionales desempeñarán un papel importante en la conversación.

Teniendo en cuenta la importancia que estaba adquiriendo el castellano en el siglo XVI, hemos creído conveniente hacer primero un breve recorrido por el Renacimiento para situar el Diálogo en la tradición de la enseñanza del español a extranjeros y, a continuación, una valoración de la obra de Valdés desde un punto de vista pragmático y didáctico, puesto que se podría considerar iniciador de un recorrido que continuará con los distintos métodos de enseñanza del español como lengua extranjera propuestos a lo largo de la historia hasta llegar a la actualidad, ya que la estructura del diálogo que adopta la obra, los recursos humorísticos y las estrategias conversacionales, así como el empleo de refranes son aspectos que se siguen tratando cinco siglos después en el proceso de enseñanza-aprendizaje de una lengua y demuestran, de esta manera, el carácter innovador de la obra, además de constituir todo un testimonio del estado del español en la época renacentista.

1. Según los datos biográficos recopilados en las ediciones de Lapesa (1965), Lope Blanch (1969) y Barbolani (1984), podemos decir que Juan de Valdés nació en Cuenca alrededor de 1510 y pasó su primera juventud en Escalona y Alcalá. En Escalona formó parte de la servidumbre de don Diego López Pacheco, marqués de Villena, y allí debió de recibir formación religiosa. Años después se trasladó a Alcalá de Henares donde realizó sus estudios e inició su correspondencia con Erasmo de Rotterdam que influirá en su vida y obra. Huyendo de la Inquisición se trasladó primero a Roma y después a Nápoles, donde fue nombrado archivero por el emperador y falleció en 1541. Entre sus obras podemos destacar: el Diálogo de doctrina cristiana (1529), el Diálogo de la lengua (1535), el Alfabeto cristiano (1546), las Ciento y diez consideraciones divinas (1550), varias traducciones y algunos tratados religiosos que circularon manuscritos entre sus discípulos. 


\section{La enseñanza del español como lengua extranjera en el Renaci- miento}

El Renacimiento trajo consigo el interés por el estudio y el conocimiento de las lenguas vulgares, hecho que ya se evidencia en la Gramática de la lengua castellana (1492) de Antonio de Nebrija, ilustre andaluz que escribió la primera gramática en lengua castellana y que, según se desprende del "Libro V"2, tuvo en cuenta no solo a nativos, como destinatarios de la misma, sino también a extranjeros para su aprendizaje. Es, precisamente, en este "Libro V" donde se observa —como dice Martínez González (1990: 619) - una finalidad didáctica para extranjeros, a diferencia del resto de libros que conforman la Gramática dirigidos a hablantes nativos, en los que se atiende a la fijación de la lengua y a la necesidad de facilitar el conocimiento del latín. Sin embargo, esta diferenciación en función del destinatario al que fuese dirigida la gramática, "no fue captada por los autores posteriores que se limitaron a hacer gramáticas del castellano pensando en su utilidad como métodos para aprender la lengua un extranjero" (Martínez González, 1990: 619). A pesar de la innovación que se percibe en la Gramática que tiene en cuenta a distintos aprendientes, "parece que la obra de Nebrija pudo servir de guía a gramáticos y profesores, pero no de libro de texto” (Martínez González, 2009: 37).

En función de la necesidad del aprendiente, cada obra atenderá a un uso distinto y con esto nos referimos a la finalidad para la que se aprendía la lengua, es decir, no es lo mismo aprender una lengua para comunicarse que para profundizar sobre el conocimiento de la misma. En este sentido, la conversación era, por tanto, primordial para los viajeros, comerciantes o militares de la época que, por las relaciones existentes entre distintas naciones en la Europa del siglo XVI, querían comunicarse con una mayor facilidad (Marcos Sánchez, 2006: 500). De ahí que, este tipo de aprendiz de idiomas, necesitara atender en primera instancia al uso comunicativo mediante unas cuantas reglas básicas sobre gramática y léxico que le permitieran — como señala Marcos Sánchez (2006: 500) — hablar y moverse por los distintos territorios con comodidad.

\footnotetext{
2. Como sabemos el "Libro V" de la Gramática de la lengua castellana lleva por título "De las introducciones de la Lengua castellana para los que de estraña lengua querrán deprender", es decir, dedica esta parte para hacer llegar la gramática castellana a extranjeros. Asimismo, se observa esta misma intención tanto en el "Prólogo" de la Gramática: "[...] entonces, por esta mi Arte, podrían venir en el conocimiento della, como agora nos otros deprendemos el arte de la gramática latina para deprender el latín. I cierto assí es que no sola mente los enemigos de nuestra fe, que tienen ia necessidad de saber el lenguaje castellano, mas los vizcainos, navarros, franceses, italianos, $\tau$ todos los otros que tienen algún trato $\tau$ conversación en España $\tau$ necesidad de nuestra lengua, si no vienen desde niños a la deprender por uso, podrán la más aína saber por esta mi obra" (Nebrija, 1992 [1492]: 16-17) como en el breve "Prólogo" que precede al "Libro V": "[...] daremos introduciones de la lengua castellana, para el tercero género de ombres, los cuales de alguna lengua peregrina querrán venir al conocimiento de la nuestra” (Nebrija, 1992 [1492]: 157).
} 
La solución a esta necesidad de comunicación la encontramos en vocabularios, coloquios y diálogos destinados al aprendizaje del latín y otras lenguas. Esta orientación didáctica con fines eminentemente prácticos en el uso de una lengua vulgar, que se remonta a la Edad Media ${ }^{3}$, se observa en un tratado para el aprendizaje del francés por parte de ingleses, de finales del siglo XIII, titulado Le trayatyz que mounsire Gautier de Bibelesworth fist a ma dame Dyonisie de Mounchensy pur aprise de langage de Walter de Bibbesworth que incluye "alguna información gramatical y, sobre todo, palabras y frases de la vida diaria, contextualizadas en textos narrativos versificados" (Sánchez Pérez, 1992: 15). De 1340 data otro manual, de interés similar, también para la enseñanza del francés elaborado por un profesor para sus alumnos en Brujas (Bélgica) y, posteriormente, en 1483 se publicará un libro de conversación de William Caxton, impreso a doble columna en francés e inglés, titulado Dialogues in French and English dirigido a comerciantes que quisieran mercadear y comunicarse con otros países, como indica el prólogo del propio libro (Sánchez Pérez, 1992: 17).

A esta tradición dialógica también se une Erasmo de Rotterdam a través de sus Colloquia puerilia (1518), cuya finalidad era la enseñanza del latín. Será Erasmo de Rotterdam quien influya directamente en Valdés a la hora de adoptar el género del diálogo en su obra, forma esta que estaba de moda en la época (Hassler, 2000: 60). Hasta 1520 (Amberes), exceptuando el Vocabulario arábigo en lengua castellana de Pedro de Alcalá (1505), no aparece la primera obra (citado por Gallardo, 1863-1889), de carácter políglota, que incorpora el español como lengua de aprendizaje y que emplea tanto diálogos como listas de palabras: el Vocabulario para aprender francés, español y flamini (Martínez González, 2009: 37).

En lo que respecta a la tradición conversacional, el Diálogo de la lengua de Juan de Valdés -obra que aquí analizamos - ha llegado hasta nosotros a través de tres manuscritos que "se encuentran en la Biblioteca Nacional, en la biblioteca del Escorial y en el Museo Británico" (Hassler, 2000: 65, nota 3) y que representan un valioso conjunto de ideas lingüísticas para la praxis de una lengua en un momento en el que se prestaba atención a la cuestión lingüística en Italia y que, en cierto modo, también se extendió a la lengua castellana (Bahner, 1966: 59). Así, Lope Blanch (1986: 51) sitúa a Valdés entre los autores que "corresponde el mérito de haber iniciado la enseñanza de la lengua española en Italia” y, del mismo modo, Blecua (2008: 26) pone de manifiesto la importancia del Diálogo como testimonio del estado de nuestra lengua en el siglo XVI y su relación con la enseñanza del español a extranjeros en la Italia Renacentista.

Asimismo, Martínez González (2009: 42) hace referencia a la "preferencia por el español frente al italiano" que tenía Valdés en ese momento para predicar a sus discípulos y añade que el Diálogo es un "conjunto de normas útiles para los extranjeros que quisieran aprender el español". No nos cabe duda de la riqueza lingüística que integra el Diálogo y de la contribución que, además, supone para la senda de metodologías de lenguas extranjeras.

3. Los Nominalia medievales (especie de manuales que incluían listas de palabras para su posterior memorización con la finalidad de aprender la lengua latina) dieron paso a los primeros diálogos destinados al aprendizaje de una lengua extranjera, diálogos que incluían el léxico en un contexto comunicativo (Martínez González, 2009: 25). 
Por tanto, pasaremos ahora a analizar, desde la óptica de la metodología de lenguas extranjeras, todos aquellos aspectos que nos permitan ver el Diálogo de la lengua de Juan de Valdés como método para la enseñanza de la lengua española a extranjeros.

\section{Pragmática y oralidad en el Diálogo de la lengua}

Juan de Valdés, en distintos apartados del Diálogo de la lengua, trata una serie de aspectos lingüísticos; posiblemente el principal de ellos sea su deseo de ser entendido por sus interlocutores. Su empeño constante por aclarar las dudas de sus compañeros italianos, sirviéndose del dominio de su lengua materna, lo lleva a emplear un modelo práctico-conversacional con una finalidad pragmática y didáctica.

La pragmática, según la Real Academia Española (DLE, 2014: s. v.), se define como "la disciplina que estudia el lenguaje en su relación con los hablantes, así como los enunciados que estos profieren y las diversas circunstancias que concurren en la comunicación”. Atendiendo a dicha definición, podemos decir que el conquense nos hace partícipes de la situación de la lengua castellana en el siglo XVI a través de la conversación que mantiene con sus amigos en Nápoles; esta conversación refleja el estado del castellano que Valdés había aprendido y hablaba, castellano que por circunstancias históricas se había convertido en lengua de cultos y cortesanos tanto en Nápoles, dominio español entonces, como en otras cortes y ciudades europeas: "Porque, como veis, ya en Italia, assí entre damas como entre cavalleros se tiene por gentileza y galanía saber hablar castellano” (Barbolani, 1984: 119). Por tanto, estas palabras nos desvelan la importancia del castellano y su expansión en aquella época, momento en el que España y el castellano comienzan a adquirir gran relevancia ${ }^{4}$. Dada esta situación, Valdés decide escribir el Diálogo de la lengua, su única obra lingüística, para facilitar a sus amigos italianos "la comprensión de todo lo que les decía o escribía”5 (Lope Blanch, 1969: 11).

A través del diálogo, género propio del humanismo, y en un ambiente de cierta confianza y amistad el propio Valdés, en cuanto al tema de la lengua, dice haber "aprendido la lengua latina por arte y libros, y la castellana por uso" (Barbolani, 1984: 121), ya que, para el conquense, al contrario que Nebrija, "el conocimiento del latín es útil para un mejor aprendizaje del castellano" - como dice Barbolani (1984: 79-81) - y gracias al uso "se ha impuesto la lengua castellana en Italia”. Junto al uso,

4. Como se sabe, desde el punto de vista histórico y social, "la fuerza política y cultural que durante el reinado de Carlos $\checkmark$ se hace fuerte en toda Europa y en las tierras americanas supondrá la internacionalización de la lengua castellana, español, por todo el mundo. El español pasa a ser lengua diplomática y adquiere una relevancia que hasta ese momento ninguna lengua nacional había adquirido. El reinado de Carlos V supuso el ascenso de España a primera potencia europea" (Roca Marín, 2006).

5. Valdés incorpora a su obra géneros como el diálogo y la carta y responde de esta manera a la costumbre renacentista, ya que, a través de las cartas, recurso ficcional, inicia la plática: "Ya sabemos que la conversación entre los personajes se inicia por las preguntas que surgen al leer las cartas, escritas, lógicamente, que Valdés les envió durante su ausencia, y que las evasivas del conquense a resolverlas son puro juego literario, aunque le sirven, al mismo tiempo, para excusar cualquier error que pudiera tener en la explicación” (Martínez González, 2017: 69). 
que pertenece a su experiencia de vida y que no está en los libros (es decir, el aprendizaje se realiza a través de la práctica y la oralidad) como indica Barbolani (1984: 79), propone su máxima "escrivo como hablo" en cuanto a la reivindicación de un estilo natural, nada rebuscado, sino claro y conciso; idea que aplica tanto a lo escrito como a lo hablado.

Según Martínez González (2017: 77), ante la diversidad de opiniones, el "escribo como hablo puede ser considerado como una manera de promover una escritura destinada a ser leída en voz alta, una escritura que se atuviera fielmente a la forma de la palabra en la conversación, como propuso Quintiliano". Además, nos recuerda que Valdés propone naturalidad y una ortografía alejada de toda afectación, porque predicaba a sus discípulos y quería, como Martín Lutero y Erasmo de Rotterdam, respetar los textos religiosos, lo que le lleva a proponer la naturalidad en la lengua hablada y escrita, lejos del artificio retórico de la época, naturalidad que une respecto al texto escrito:

Valdés no solo pretende que la escritura refleje la pronunciación, sino que marca, como dice Gauger, el alejamiento de la ortografía afectada e influida por el latín y la consideración del castellano como lengua con identidad propia frente al latín. Pero la idea no es de Valdés, aparece ya en Quintiliano (Institutio oratoria, c. 95 d. C., Lib. I, cap. VII, § 30): “Ego, nisi quod consuetudo optinuerit, sic scribendum quidque iudico quomodo sonat”. (Martínez González, 2017: 67)

Valdés idea una especie de guía práctica de la lengua castellana, aunque entre sus intenciones también se encontraba llevar a cabo su labor religiosa. De ahí que debiera predicar su lengua, pero ateniéndose a la fidelidad de los textos, postura humanista que defiende a lo largo del Diálogo.

Asimismo, innova en cierto modo al atribuir gran importancia a la oralidad en el aprendizaje de una lengua. Desde su punto de vista, nos asegura que con tres reglas generales ${ }^{6}$ de gramática se aprende a hablar y escribir en nuestra lengua, aunque también debemos tener en cuenta que en numerosas ocasiones arremete contra Nebrija por su Gramática de la lengua castellana (1492) y su Vocabulario español-latino (1495), obras que quizás no estaban "al alcance del público napolitano" (Hassler, 2000: 60), porque "los italianos no disponían aún de ninguna gramática española que les hubiera permitido aprender, por sí mismos, la lengua castellana. Habrían de pasar todavía bastantes años antes de que se publicaran en Italia las excelentes Osservationi de Juan de Miranda" (Lope Blanch, 1969: 11), aunque Valdés sí las conocía. No obstante, Valdés y Nebrija, a pesar de sus diferencias, demuestran su adelantamiento a la época con sus estudios y, al mismo tiempo, contribuyen a la fijación de la lengua. Nuestro autor dice no conocer la gramática castellana, porque ha aprendido la lengua por uso y no por libros y, por lo tanto, parece que sus conocimientos sobre gramática no

6. Valdés señala tres reglas generales en cuanto a la gramática: en primer lugar, los vocablos que no se parecen a los latinos o griegos son arábigos, en los cuales se puede ver $h, x o z$. Además, apunta que las palabras que empiezan por al-, az-, ha-, en-, gua-, $x a-$ o xe- son de origen árabe. En segundo lugar, hace observaciones sobre el uso del artículo. En tercer lugar, hace referencia a la importancia que tiene el acento, ya que puede cambiar el significado. Es el primer español que hace observaciones sobre la colocación de la tilde en algunas palabras. 
son muy profundos, aunque sabía explicar el uso de la lengua a sus contertulios cuando conversaba sobre la lengua castellana.

Valdés utiliza la función metalingüística para hablar sobre la lengua, como ya hemos dicho, y también hace uso de la oralidad que, como indica, por ejemplo, Agustín Llach (2007: 162), "adquiere un valor trascendental en los procesos de enseñanza-aprendizaje de lenguas extranjeras". Esta importante función de la oralidad en el proceso de enseñanza-aprendizaje de una lengua extranjera es la que observamos en el Diálogo, donde Valdés responde a las preguntas que les surgen a sus discípulos italianos tras la lectura de las cartas escritas, motivo por el que se inicia la conversación y por el que se hace necesaria la comunicación oral.

Todos sabemos la repercusión que tiene la comunicación en el aprendizaje y el papel fundamental que juega la oralidad. Tan importante es saber hablar una lengua como escribirla, es decir, dominar las destrezas orales (escuchar y hablar) y las destrezas escritas (leer y escribir) son el objetivo principal del proceso de adquisición de una lengua. Ahora bien, también hemos podido comprobar en la praxis de una lengua extranjera que la competencia comunicativa y su desarrollo es fundamental en nuestras vidas, teniendo en cuenta que el lenguaje es un hecho social y que sin sociedad las competencias perderían su valor. La lengua oral se convierte en una herramienta clave para hacer del aprendiente un hablante autónomo, capaz de desenvolverse con fluidez y eficacia en el ámbito comunicativo. En una clase de enseñanza de lenguas extranjeras, como puede ser la enseñanza del español, prima la interacción de los alumnos, el diálogo y las estrategias conversacionales, de las que trataremos más adelante. No es tarea baladí el conseguir comunicarse con personas nativas de la lengua que se estudia, sino que requiere de práctica y dedicación. Por tanto, teniendo en cuenta estas consideraciones acerca de la comunicación, vemos que este camino es el que sigue Valdés con sus discípulos a la hora de tratar cuestiones sobre la lengua castellana.

Partiendo de la importancia de la comunicación en la enseñanza de una lengua, resulta de cierto interés hacer mención al modelo clásico de comunicación verbal de Jakobson (1975: 352-353) que, a su vez, podemos aplicar al Diálogo: 
Tabla 1: Modelo clásico de comunicación verbal y las funciones del lenguaje ${ }^{7}$ de Jakobson

\begin{tabular}{|c|c|}
\hline \multicolumn{2}{|c|}{ Diálogo de la lengua } \\
\hline $\begin{array}{c}\text { Elementos del modelo clásico de comunicación } \\
\text { verbal }\end{array}$ & Funciones del lenguaje \\
\hline Emisor: Valdés y sus amigos & $\begin{array}{l}\text { Función expresiva: Marcio.- ¡O cómo perseve- } \\
\text { ró diestramente en la metáfora! (Barbolani, } \\
\text { 1984: 214). }\end{array}$ \\
\hline $\begin{array}{c}\text { Mensaje: preguntas y comentario sobre las } \\
\text { cartas }\end{array}$ & $\begin{array}{l}\text { Función poética: Valdés.- [...] "Quien a buen } \\
\text { árbol se arrima, buena sombra lo cobija” } \\
\text { (Barbolani, 1984: 197). }\end{array}$ \\
\hline Receptor: Marcio, Coriolano, Torres, Valdés & $\begin{array}{l}\text { Función apelativa: Valdés.- Empeçad a pregun- } \\
\text { tar, que yo os responderé (Barbolani, 1984: 128). }\end{array}$ \\
\hline Código común: lengua castellana & $\begin{array}{l}\text { Función metalingüística: Marcio.- Pues ipor qué } \\
\text { no ponéis la por artículo a todos los nombres } \\
\text { femeninos? Valdés.- [...] Esto hazemos por evi- } \\
\text { tar el mal sonido que hazen dos aes juntas } \\
\text { ( Barbolani, 1984: 149-150). }\end{array}$ \\
\hline $\begin{array}{c}\text { Contexto extralingüístico: conversación sobre } \\
\text { las cartas tras la comida }\end{array}$ & $\begin{array}{l}\text { Función referencial: Valdés.- Solamente pongo } \\
\text { e quando el vocablo que se sigue comiença en } i \\
\text { (Barbolani, 1984: 165). }\end{array}$ \\
\hline Canal físico: conversación fijada por escrito & $\begin{array}{c}\text { Función fática: Valdés.- [...] ¿Oyes? dame el } \\
\text { cavallo (Barbolani, 1984: 264). }\end{array}$ \\
\hline
\end{tabular}

Durante el acto comunicativo, el emisor utiliza la lengua con una intención concreta (Valdés hace de emisor cuando está explicando aspectos de la lengua; postura muy similar la que pueden adoptar los profesores en clase de español como lengua extranjera, salvando las distancias temporales y metodológicas, cuando enseñan la lengua y la cultura) mientras que el receptor (en nuestro caso, los amigos napolitanos del conquense o trasladándonos al momento actual los alumnos del aula de español) puede interpretar el mensaje recibido del emisor y otorgarle un punto de vista propio, sin que coincida exactamente con la intención inicial del emisor. Sin embargo, la actitud del receptor, tanto en el Diálogo como en una clase, no es pasiva, sino que la interacción existe y el esquema se convierte en una estructura circular permitiendo que los interlocutores puedan ser emisores y receptores al mismo tiempo en el transcurso del diálogo.

7. Jakobson decidió completar el modelo establecido anteriormente por el lingüista alemán Karl Bühler (defendía la existencia de tres funciones: expresiva, representativa y apelativa) y añadió tres funciones más: metalingüística, poética y fática. 


\subsection{Uso dialógico como forma de aprendizaje del español como lengua extranjera}

El diálogo en sí, es decir, la forma de organización del discurso que adopta Valdés es una muestra de su finalidad práctica en lo que concierne al aprendizaje de la lengua. La estructura que sigue está destinada a mejorar el conocimiento del español desde la naturalidad y la claridad. Para aprender la lengua a través del uso, los alumnos deben atreverse a comunicar e intercambiar ideas para poder reforzar la conversación, así como se evidencia en las intervenciones del Diálogo de la lengua, donde Valdés accede a contestar el programa de preguntas planteado por sus compañeros italianos. En sus explicaciones tendía a la sencillez para evitar posibles confusiones o errores, especialmente en lo referente a su misión religiosa, hecho que tanto preocupaba a Valdés como afirma Martínez González (2017: 62-63):

Preocupado por la exactitud y por no inducir a error a nadie, Valdés opta por hablar en castellano, su lengua materna que dominaba perfectamente, y por utilizar, igualmente, esta lengua en sus traducciones y escritos [...] Valdés prefería que fueran sus discípulos los que no comprendieran o erraran, a ser él la causa de su equivocación. Ese hecho es el que le lleva a la sencillez y a alejarse de la grandilocuencia; los adornos, la afectación, podían llevar a la confusión.

El castellano es la lengua que elige Valdés para su predicación religiosa, pero, para que sus discípulos italianos entendieran mejor lo que les transmitía por escrito, tenía que "dar consejos respecto a usos lingüísticos" (Lapesa, 1965: 13) y es, precisamente, en el Diálogo donde da respuesta a las preguntas planteadas por su círculo napolitano. A través de sus explicaciones sobre cuestiones lingüísticas vemos cómo, en lo que respecta a ciertas soluciones acerca de los problemas de la escritura y la pronunciación ${ }^{8}$, el tiempo le ha acabado dando la razón.

El género dialógico es el empleado por Valdés para resolver las dudas de sus amigos y, por esta razón, conviene analizar ahora en el Diálogo, tras haber aplicado el modelo clásico de comunicación verbal de Jakobson, todos aquellos rasgos que caracterizan "la situación de enunciación oral prototípica" (Calsamiglia y Tusón, 2012: 18)9:

8. Valdés acertará, en líneas generales, con sus propuestas léxicas como dice Lapesa (1986: 310): "A pesar de que en las preferencias de Valdés no faltan arbitrariedades, y aunque no pocas de sus reglas son caprichosas, su elección coincide por lo general con las tendencias que habían de prevalecer: así recomienda vanidad, invernar, abundar, cubrir, començar, tropeçar, avergonçar, de ponerlos, por traerlos, ponedlo, dezirlo, hazerlo, que han sobrepuesto a sus oponentes vanedad, envernar, abondar, cobrir, escomençar, estropear, envergonçar, de los poner, por los traer, ponedlo, dezillo, hazello".

9. Nos basaremos en Calsamiglia y Tusón (2012) para realizar el análisis del uso dialógico de la obra de Valdés. 
- Participación simultánea. Valdés y sus amigos napolitanos son los interlocutores del Diálogo:

Valdés.- ¿A qué propósito me queréis obligar tan estrechamente? ¿Avéisos por ventura concertado todos tres para el mohíno? Ora sus, sea lo que fuere, digo que os doy mi fe que responderé como mejor supiere a todo lo que esta tarde me querréis preguntar. ¿Estáis contentos?

Marcio.- Yo por mi parte estoy contentíssimo.

Coriolano.- A mí harto me basta.

Torres.- Pues para mí no era menester más que la primera promessa. (Barbolani, 1984: 118)

- $\quad$ Presencia simultánea. La plática se inicia en la sobremesa y en un lugar tranquilo para poder llevar a cabo la enseñanza de su lengua materna a través de apacibles conversaciones, sin olvidar su actividad religiosa:

Marcio.- Pues los moços son idos a comer y nos an dexado solos, antes que venga alguno que nos estorve, tornemos a hablar en lo que comencé a deziros esta mañana.

Valdés.- No me acuerdo de qué cosa queréis dezir. (Barbolani, 1984: 117)

- Relación interpersonal. Cooperación, cortesía, respeto y confianza son aspectos que confluyen en la relación entre Valdés y sus amigos italianos. Las relaciones entre los personajes son más complejas de lo que parece, como apunta Barbolani, en el panorama del Diálogo, donde los interlocutores (Valdés, Marcio, Coriolano y Torres) negocian en la interacción y construyen una relación interpersonal basada en sus características psicosociales:

Torres.- Yo os prometo, si no fuesse cosa contraria a mi professión, que me avría, algunos días ha determinadamente puesto en hazer un libro en la lengua castellana como uno que diz que Erasmo ha hecho en la latina, allegando todos los refranes que hallasse, y declarándolos lo menos mal que supiesse, porque he pensado que en ello haría un señalado servicio a la lengua castellana.

Valdés.- También era Julio César de vuestra professión, pero no tuvo por cosa contraria a ella con la pluma en la mano escrivir de noche lo que con la lança hazía de día, de manera que la professión no os escusa. ¿No avéis oído dezir que "las letras no embotan la lança”? (Barbolani, 1984: 127)

El diálogo, como tal, es la manifestación más usual de la oralidad, ya que intervienen interlocutores en la comunicación como factor social común. En el Diálogo, esta oralidad se nos presenta escrita a través de las cartas (motivo por el cual se inicia la conversación) a las que responde Valdés y para asegurar que todo queda recogido por escrito Marcio decide que Aurelio se va a encargar de tomar nota de todo lo que se habla, mientras que él se ocupa de llamar a Valdés: 
Marcio.- Avéislo pensado muy bien; hágase assí: poned a messer Aurelio que, como sabéis, es entendido en entramas lenguas, y ordenadle lo que ha de hazer, mientras que yo voy a llamar a Valdés, que lo veo passear muy pensativo. (Barbolani, 1984: 130-131)

Calsamiglia y Tusón (2012: 311) recurren a la obra ${ }^{10}$ que está siendo objeto de estudio a lo largo de estas páginas, para ejemplificar la estructura dialogal, aunque al parecer "no nos encontramos ante una estructura en la que una secuencia funcione como envolvente de otra u otras que se incrustan en ella", sino que lo que "se observa es que un texto de orientación explicativa utiliza la forma dialogal para estructurar esa función discursiva”, es decir, el Diálogo sirve como base organizadora de "la explicación de un texto del Renacimiento", que es la propia obra o, más concretamente, el comentario que surge de las cartas que Valdés escribe a sus amigos.

En el discurso oral que mantienen Valdés y sus amigos encontramos características lingüístico-textuales que pueden ser analizadas desde distintos niveles:

a) Nivel fónico

Para Valdés, la solución a las dudas sobre la forma de escribir una palabra se encuentra en la pronunciación; justificación que también podemos encontrar —en sentido literal- a través de su máxima escribo como hablo:

Marcio.- Bien me plaze esso; pero ¿por qué scrivís truxo, escriviendo otros traxo?

Valdés.- Porque es a mi ver más suave la pronunciación, y porque assí lo pronuncio desde que nací. (Barbolani, 1984: 158)

Valdés.- [...] quando escrivo para castellanos y entre castellanos, siempre quito la $g$, y digo sinificar y no significar, manífico y no magnífico, dino y no digno; y digo que la quito porque no la pronuncio [...]. (Barbolani, 1984: 174)

Estos ejemplos son una muestra de la importancia que tiene la pronunciación en la escritura para el conquense, pero -como señala Barbolani (1984: 179, nota 136) - resulta interesante mencionar el momento en el que transmite la necesidad de simplificar el sistema ortográfico de las lenguas vulgares:

Valdés.- Los que lo escriven con $p$ darán cuenta de sí; yo escrívolo con $f$ por conformar mi escritura con la pronunciación. (Barbolani, 1984: 179)

10. El fragmento elegido pertenece al momento en el que se está tratando sobre el léxico y la posible influencia de vocablos, procedentes de otras lenguas, en la lengua castellana, Barbolani, 1984: 143-144. 
b) Nivel morfosintáctico

La improvisación, característica del discurso oral, provoca en la forma de hablar de los interlocutores cierta inseguridad, duda o certeza mediante expresiones como las que emplea Valdés cuando está hablando del origen etimológico de las palabras: "También creo que quedassen del griego trévedes y chimenea, y aun brasa y abrasar [...]" (Barbolani, 1984: 134) y del origen italiano de algunos vocablos: "Bien creo que aya también algunos otros vocablos tan propios castellanos que, sin tener origen de ninguna otra lengua, con el tiempo an nacido en la provincia” (Barbolani, 1984: 143). Valgan estos dos ejemplos para apreciar el significado de la expresión yo creo que, por orden de aparición, expresa incertidumbre y seguridad. Además, en la relación entre emisor y receptor pueden darse expresiones que conllevan a la interacción y la expresión: "Picastes; pues más de otras diez vezes os haré picar de la mesma manera” (Barbolani, 1984: 161) y “Éssa sería una gentil cossa! No creo que vos caeréis en essa indiscreción" (Barbolani, 1984: 262).

\section{c) Organización textual y discursiva}

La misión que tienen los marcadores, como establecen Martín Zorraquino y Portolés Lázaro (1999: 4057), es la de guiar en el discurso teniendo en cuenta sus distintas propiedades morfosintácticas, semánticas y pragmáticas como unidades lingüísticas. En el Diálogo de la lengua, de una forma generalizada, se evidencia de mayor a menor frecuencia de uso los siguientes marcadores del discurso ${ }^{11}$ : pues, por tanto, ahora, en efecto, por el contrario, sin duda. El marcador más usado en el Diálogo es pues: "Torres. - Pues para mí no era menester más que la primera promessa" (Barbolani, 1984: 118) que Martín Zorraquino y Portolés Lázaro (1999: 4083) integran en su clasificación dentro de los marcadores del tipo comentadores.

Durante la consulta de los marcadores, hemos creído conveniente ejemplificar la aparición de cada uno de los marcadores discursivos en la obra, así como quién hace uso de los mismos (Valdés, Torres, Coriolano o Marcio):

11. Ante las múltiples clasificaciones que podemos encontrar en la actualidad sobre los marcadores del discurso en la lengua española nos hemos decantado por la de Martín Zorraquino y Portolés Lázaro (1999: 4080-4081); esta clasificación distingue cinco grupos: estructuradores de la información, conectores, reformuladores, operadores argumentativos y marcadores conversacionales. 
Tabla 2: Tipos de marcadores del discurso en el Diálogo de la lengua

\begin{tabular}{|c|c|c|}
\hline Marcadores discursivos & Tipos & Ejemplos \\
\hline Pues & $\begin{array}{l}\text { Estructurador de la informa- } \\
\text { ción. Comentador }\end{array}$ & $\begin{array}{c}\text { Torres.- Pues para mí no era } \\
\text { menester más que la primera } \\
\text { promessa (Barbolani, 1984: } \\
\text { 118). }\end{array}$ \\
\hline Por tanto & Conector consecutivo & $\begin{array}{l}\text { Valdés.- Pues sabed que lo es; } \\
\text { por tanto os guardad de caer } \\
\text { en él, y también de caer en otro } \\
\text { que es a mi parecer aún más } \\
\text { feo que éste [...] (Barbolani, } \\
\text { 1984: 236). }\end{array}$ \\
\hline Ahora & Conector contraargumentativo & $\begin{array}{l}\text { Valdés.- Si no adornárades } \\
\text { esta vuestra demanda con } \\
\text { tanta retórica, liberalmente me } \\
\text { ofreciera a obedeceros; ahora, } \\
\text { viendôs venir ataviado en vues- } \\
\text { tra demanda con tantas razo- } \\
\text { nes, sospechando me queréis } \\
\text { meter en qualque cosa enojo- } \\
\text { sa, no sé qué responderos, si } \\
\text { primero no me dezís claramen- } \\
\text { te qué es lo que queréis de mí ( } \\
\text { Barbolani, 1984: 118). }\end{array}$ \\
\hline En efecto & $\begin{array}{l}\text { Marcador conversacional de } \\
\text { modalidad epistémica }\end{array}$ & $\begin{array}{l}\text { Marcio.- Tenéis razón, y en } \\
\text { efecto es assí, que en todas las } \\
\text { lenguas del mundo ay unos } \\
\text { que scriven mejor, más propia } \\
\text { y más galanamente que otros } \\
\text { [...] (Barbolani, 1984: 238). }\end{array}$ \\
\hline
\end{tabular}




\begin{tabular}{|c|c|c|}
\hline Por el contrario & Conector contraargumentativo & $\begin{array}{l}\text { Valdés.- [...] si diziendo "Quien } \\
\text { haze un cesto hará ciento", en } \\
\text { el haze ponéis el acento en la } \\
\text { última haciéndolo imperativo, } \\
\text { gastaréis la sentencia, y por el } \\
\text { contrario si diciendo "Quien } \\
\text { sufrió calló y vido lo que quiso" } \\
\text { en el calló ponéis el acento } \\
\text { en la a, haziéndolo presente, } \\
\text { no diréis nada [...] (Barbolani, } \\
\text { 1984: 152). }\end{array}$ \\
\hline Sin duda & $\begin{array}{c}\text { Marcador conversacional de } \\
\text { modalidad epistémica }\end{array}$ & $\begin{array}{c}\text { Torres.- Sin dubda creo que } \\
\text { sea assí (Barbolani, 1984: 145). }\end{array}$ \\
\hline
\end{tabular}

El grado de dominio de una lengua puede verse a través de los marcadores del discurso empleados en la conversación, como podemos observar en dos de los interlocutores del Diálogo: Marcio (habla y entiende la lengua, pero no sabe escribirla) y Coriolano (se acaba de iniciar en la lengua, por lo que no la conoce bien). Esta situación del aprendizaje de la lengua castellana en la que se encuentran los amigos italianos de Valdés nos permite acercarnos al uso de los marcadores del discurso que hacen los dos interlocutores y establecer diferencias en su conocimiento y uso de estas unidades lingüísticas. Por un lado, Marcio, situado en un nivel más avanzado que Coriolano, emplea marcadores como: por tanto, ahora, en efecto o pues; por otro lado, Coriolano que se está iniciando en la lengua utiliza un único marcador en cinco ocasiones (pues) debido a su menor dominio del castellano. Esta situación en la que se encuentran Marcio y Coriolano en cuanto al aprendizaje de la lengua castellana explica que el número de intervenciones de Marcio sea mayor que el de Coriolano y que las preguntas de Coriolano sean más ingenuas.

d) Nivel léxico

A lo largo del Diálogo Valdés dedica una gran parte de la conversación a comentar las estructuras léxicas y hace

preciosos comentarios sobre voces "impropias" del castellano, sobre vulgarismos y rusticismos, sobre arcaísmos y neologismos de varia procedencia (helenismos, latinismos e italianismos especialmente) sobre voces de origen árabe y sobre dialectalismos peculiares de diversas regiones de la Península Ibérica. (Lope Blanch, 1969: 22)

Por tanto, a través de vulgarismos, muchos de los cuales nos parecen actualmente de uso culto (raudo, lóbrego o erguir), arcaísmos (asaz, artero o alevoso) y neologismos (manejar, novela o pedante), como informa Lope Blanch (1969: 22-26), nos aporta una amplia visión del léxico de la época. 
Por otro lado, en lo que respecta a la enseñanza de la lengua, el conquense opta por buscar aquellas palabras castellanas que tuvieran mayor similitud con las italianas para facilitar el aprendizaje del vocabulario a sus amigos italianos. El parecido entre el castellano y el italiano, lenguas romances, permitía a Valdés utilizar con ingenio los vocablos de una lengua y de otra; por ejemplo, en lugar de sortija y acostamiento dice anillo y salario (anello y salario en italiano) por proximidad con la lengua italiana:

Valdés.- Que voy siempre acomodando las palabras castellanas con las italianas, y las maneras de dezir de la una lengua con las de la otra, de manera que, sin apartarme del castellano, sea mejor entendido del italiano.

Torres.- ¿ ¿De qué manera hazéis esso?

Valdés. - Yo os diré. Quanto a las palabras, si tengo de dezir: "Honra sin provecho, sortija en el dedo", por sortija digo anillo; si puedo dezir salario, no digo acostamiento.

Marcio. - ¿Es lo mesmo acostamiento que salario?

Valdés. - Lo mesmo.

Marcio. - Nunca oí esse vocablo. (Barbolani, 1984: 227)

Hemos comprobado la importancia del diálogo como género en la enseñanza de una lengua, pero también podemos encontrar otros factores que influyen en el desarrollo de la comunicación, como pueden ser las estrategias conversacionales o la espontaneidad que logran la relación e intercambio de opiniones entre los interlocutores.

\subsection{Estrategias conversacionales: cortesía e ironía}

En toda conversación hay una lucha por convencer al contrario como se puede apreciar en el discurso que mantienen los cuatro amigos de los cinco personajes del Diálogo, porque debemos recordar que la actitud de Aurelio es pasiva (su labor es escribir todo aquello que se va comentando, como hemos indicado anteriormente); pero como ya sabemos, la cortesía y el respeto también están presentes en la relación amistosa de los interlocutores:

Marcio.- Perdonadme por esta vez, que fue sin malicia. (Barbolani, 1984: 168)

Valdés.- Vuestra cortesía me obliga más que mi promessa; por tanto avéis de saber que, quando yo hablo o escrivo, llevo cuidado de usar los mejores vocablos que hallo, dexando siempre los que no son tales [...]. (Barbolani, 1984: 194)

Marcio.- Muy bien vais; proseguir adelante, que me dais la vida. (Barbolani, 1984: 198)

Valdés.- De buena voluntad os diré todos los que me vernán a la memoria. De la lengua griega desseo introduzir éstos que stan medio usados: paradoxa, tiranizar, idiota, ortografía. (Barbolani, 1984: 219) 
En esta ocasión, el Diálogo sirve para mejorar el conocimiento y uso de la lengua de nuestros dos contertulios italianos: Marcio (se sitúa en un nivel mayor de la lengua) y Coriolano (se está iniciando en la lengua), aunque no debemos olvidar la presencia entre ellos de un español, Torres. Los tres contertulios contarán con la ayuda de Valdés para disipar dudas, perfeccionar y corregir el uso de la lengua castellana.

Teniendo en cuenta el valor y la gran significación de la comunicación en la enseñanza de una lengua, podemos decir que existen una serie de fenómenos pragmáticos que se aplican a través de distintas tácticas y estrategias en el acto comunicativo y atienden a un propósito por parte del hablante. Así pues, el Diccionario de términos clave de ELE define las tácticas y estrategias pragmáticas como "todos los recursos (tanto verbales como no verbales) que el hablante de una lengua utiliza de forma consciente para construir e interpretar los discursos de forma apropiada al contexto y para interactuar con eficacia en la comunicación" e impregnan, a su vez, componentes del tipo gramatical, pragmático-discursivo, nocional, cultural y de aprendizaje (s. v. tácticas y estrategias pragmáticas). De este modo, Valdés, defensor de un estilo natural y alejado de toda afectación, es partidario de que el estilo vaya "bien acomodado a las personas que hablan" (Barbolani, 1984: 255) y "diferencia en el alçar o abaxar el estilo" (Barbolani, 1984: 233) según lo que escribe o la persona a la que escribe. De ahí que el Diálogo impregne la idea de naturalidad, contraria a algunas nociones de Nebrija, y Valdés emplee los refranes para ejemplificar sus explicaciones.

En consonancia con lo anterior, sería adecuado hacer alusión a las distintas estrategias que se aprecian en el Diálogo: la ironía y la cortesía.

Valdés recurre a la ironía para hacerse de rogar al principio de la conversación: "No me acuerdo de qué cosa queréis dezir" (Barbolani, 1984: 117). o acabar rápido: "Hazedlo por lo que os cumple, que a mí poco me importa. Más me cumple acabar esta jornada de oy, y por esto passo a la tercera regla” (Barbolani, 1984: 151). Sin embargo, la ironía desaparece cuando se preocupa por no inducir a error a sus amigos y los invita a que cuestionen sobre un tema que acaba de comentar como, por ejemplo, puede ser el origen del castellano: "Aunque el creer sea cortesía, yo huelgo que desto que os he dicho no creáis más de lo que viéredes” (Barbolani, 1984: 133). Esta inseguridad o falta de certeza se observa en alguna que otra ocasión en el Diálogo como puede ser en la proveniencia de alguna palabra: "Pienso yo que jornal, jornalero y jornada an tomado principio del GIORNO que dezís acá en Italia; es verdad que también se lo puede atribuir assí Cataluña” (Barbolani, 1984: 143).

Del mismo modo, Marcio ironiza, pero muy cortésmente cuando plantea la ronda de preguntas que le tiene preparada a Valdés y lo hace a través de la pregunta “¿Conténtaos esta manera de proceder?" (Barbolani, 1984: 130); su forma de iniciar la propuesta, indicar el orden de preguntas y hacer cuestiones elaboradas pone de manifiesto, una vez más, que su nivel de la lengua castellana es mayor que el de Coriolano. La ironía también la utiliza con Valdés cada vez que menciona a Nebrija: 
Marcio.- Pues Librixa...

Valdés.- No aya más Librixa por vuestra vida.

Marcio.- Picastes; pues más de otras diez vezes os haré picar de la mesma manera. (Barbola-

ni, 1984: 161)

Cada interlocutor hace uso de forma distinta de las estrategias conversacionales, pero el humor ocupa un lugar fundamental en el Diálogo, como veremos a continuación de forma más exhaustiva.

\subsection{Humor y espontaneidad como recursos didácticos}

En la oralidad, según el nivel de los aprendientes, intervienen numerosas microdestrezas, entre las cuales podemos destacar: "Manejar el sentido figurado, el doble sentido, los juegos de palabras, la ironía, el humor en general” (Diccionario de términos clave de ELE, s. v. expresión oral). El humor, que tan manifiesto está en el Diálogo de la lengua, se encuentra relacionado con la espontaneidad en el discurso oral, bien sea mediante expresiones humorísticas o chistes que se incorporan al diálogo, ya que, como todos sabemos, "el humor es un elemento dinámico con una enorme potencialidad expresiva que sirve para mantener la atención del oyente, por lo que también tiene el efecto de entablar y mantener relaciones sociales" (Ojeda Álvarez y Cruz Moya, 2004: 235).

En efecto, el humor sirve de ayuda en la interacción comunicativa y aporta una mayor familiaridad al discurso; prueba de ello es la utilización de expresiones, tan conocidas y comentadas del Diálogo, como "ora sus": "Ora sus, sea lo que fuere, digo que os doy mi fe que responderé como mejor supiere a todo lo que esta tarde me querréis preguntar. ¿Estáis contentos?" (Barbolani, 1984: 118), "¿Queréis que os diga la verdad?": "Queréis que os diga la verdad? Aun con todo esso pienso que me burláis" (Barbolani, 1984: 121) o "muy larga me la levantáis": "Muy larga me la levantáis; quanto que esto más es querer saber historias que gramática” (Barbolani, 1984: 131). De la misma manera, el humor se refleja en

ironías sobre su falta de humildad, con antífrasis muy del gusto de la prosa ideológica de la época (p. 63), sobre su arrogancia (p. 144), su glotonería (p. 52), sobre el desgaste semántico de palabras demasiado usadas por clérigos como "observancia" y "guardar" (p. 77) o "profesión” (p. 142), de modo que el contexto ideológico está integrado en la totalidad estructural del texto. (Lerner, 2006: 408-409)

Así pues, el humor que se percibe a lo largo de la conversación entre Valdés y sus amigos facilita no solo la interacción sobre lo que se dice en cada momento en lo que respecta a la lengua, sino que también invita a que sus contertulios participen y aporten su opinión sobre distintos aspectos. 


\section{Lengua y cultura}

Los aspectos socioculturales que impregnan las conversaciones del Diálogo favorecen la comunicación entre españoles e italianos y, además, ayudan a profundizar en el conocimiento y uso de la lengua castellana.

Durante toda la conversación se aprecia confianza y amistad "entre personas del mismo status social que practican una convivencia de modales urbanos y decorosos, una medietas alcanzada también a través del lenguaje conversacional” (Barbolani, 1984: 57).

En este caso, la conexión entre España e Italia se produce mediante la cultura que va unida a la lengua; ejemplo de ello son los refranes, que como veremos a continuación, serán de gran utilidad para Valdés en la enseñanza de su lengua materna.

\subsection{La lengua viva a través de los refranes}

Los refranes, entendidos como "dichos agudos y sentenciosos de uso común" (DLE, 2014: s. v.), son utilizados continuamente por Valdés, puesto que ante la falta de modelos lingüísticos que le sirvan de norma - como apunta Barbolani (1984: 70-71) - decide utilizarlos como "testimonio del uso auténtico y generalizado de ciertas formas léxicas y sintácticas". Efectivamente, los refranes se convierten en la mejor solución para cubrir la ausencia de obras, dado que, en su opinión -como dice Lapesa (1965: 15) - no hay obras literarias que le sirvan de referencia ${ }^{12}$.

Otro punto importante en la obra es la relación que existe entre los refranes que como ejemplo para sus explicaciones utiliza Valdés y el Vocabulario de refranes y frases proverbiales (1627) de Gonzalo Correas $^{13}$. A modo de ejemplo, hacemos referencia a algunos de los refranes recogidos por Barbolani (1984) en su edición del Diálogo de la lengua; refranes que encontramos también en la obra de Correas:

- "Dixo el asno al mulo: ¡harre allá! orejudo" (Barbolani, 1984: 145): este proverbio le sirve para explicar el uso del artículo, concretamente para referirse a la contracción de a+el por al en el masculino.

- "Al ruin dadle un palmo, y tomárase quatro" (Barbolani, 1984: 146): en este caso, al comienzo de sus observaciones sobre gramática, se sirve del refrán para mostrar cómo el pronombre aparece junto al verbo.

12. Nebrija también se encontraba en esta situación, es decir, como todos sabemos, no disponía de modelos lingüísticos que le sirvieran como norma; razón por la cual decide escribir su Gramática de la lengua castellana.

13. Sevilla Muñoz y Sardelli (2007: 69-70), por ejemplo, analizan en su estudio de forma pormenorizada las relaciones paremiológicas entre ambos autores y parten de la idea de que en la obra de Valdés encontramos no solo refranes, sino locuciones proverbiales y dialogismos, por lo que el número de refranes, considerando las apreciaciones del estudio en cuanto al significado, puede superar los 170. 
- "Trasquílenme en concejo, y no le sepan en mi casa" o "Ir por lana y volver trasquilado" (Barbolani, 1984: 182): estos dos refranes sirven para explicar el significado del verbo trasquilar y son utilizados por Torres en su conversación con Marcio y Valdés.

- $\quad$ "A perro viejo no cuz cuz" (Barbolani, 1984: 156): es utilizado como ejemplo para diferenciar los casos en los que a se escribe con $h$ o sin ella, es decir, cuando se considera verbo o preposición.

- "Al buey maldito el pelo le luze" (Barbolani, 1984: 192): en la aclaración sobre la formación de palabras a través del prefijo re- utiliza este refrán para añadir que el uso del prefijo algunas veces acrecienta la significación, pero otras la cambia (pone como ejemplo lucir frente a relucir).

De acuerdo con lo dicho anteriormente, tanto en la actualidad como en la obra de Valdés los refranes actúan como transmisores de cultura y, de igual forma, se utilizan para facilitar el aprendizaje de la lengua española. Por lo tanto, lengua y cultura se presentan unidas en el Diálogo de la lengua, obra que nos permite acercarnos a la época del conquense desde un punto de vista histórico, social, lingüístico y literario.

\section{Conclusión}

El estudio que hemos presentado del Diálogo de la lengua parte del análisis de la obra desde un punto de vista pragmático, dialógico y cultural a través de distintos aspectos y recursos utilizados por el conquense, como son la naturalidad en el diálogo, la espontaneidad, las estrategias conversacionales, el humor y los refranes, que intervienen en su enseñanza de la lengua española; aspectos que se siguen utilizando en la actualidad y que nos permiten valorar la propia obra como método de enseñanza del español para extranjeros. Esta visión del Diálogo podríamos decir que convierte a Valdés en iniciador de un camino que nos llevará hasta los actuales métodos de enseñanza del español como lengua extranjera.

En síntesis, en el Diálogo encontramos una situación comunicativa, muy propia de una clase de español como lengua extranjera, en la que Valdés quería ser entendido por sus discípulos y para ello, decidió enseñar su lengua materna y un estilo sencillo, tanto en lo oral como en lo escrito, para facilitar el aprendizaje de la lengua, labor importante que - sin olvidarnos de sus propósitos iniciales y de las circunstancias sociales y religiosas que rodearon la aparición de su obra-consigue desempeñar de la forma más natural, humana y enriquecedora: compartiendo su lengua y su cultura con un grupo de amigos que estaban dispuestos a mejorar su conocimiento y uso de la lengua castellana. 


\section{Bibliografía}

Agustín Llach, María Pilar (2007), "La importancia de la lengua oral en la clase de ELE: estudio preliminar de las creencias de aprendices", en Enrique Balmaseda (ed.), Actas del XVII Congreso Internacional de la Asociación para la enseñanza del Español como Lengua Extranjera (ASELE), vol. 1, Logroño, Universidad de la Rioja, p. 161-173.

Bahner, Werner (1966), La lingüística española del Siglo de Oro. Aportaciones a la conciencia lingüística en la España de los siglos XVI y XVII, Madrid, Ciencia Nueva.

Barbolani, Cristina (1984), Juan de Valdés: Diálogo de la lengua, $2^{a}$ ed., Madrid, Cátedra. [Edición de Cristina Barbolani, $1^{2}$ ed., 1982.]

Blecua Perdices, José Manuel (2008), “Juan de Valdés y la enseñanza del español”, en Sara M. Saz (ed.), Actas del XLII Congreso Internacional de la Asociación Europea de Profesores de Español, Málaga, Asociación Europea de Profesores de Español (AEPE), p. 25-31.

Calsamiglia Blancáfort, Helena y Amparo Tusón Valls (2012), Las cosas del decir: manual de análisis del discurso, $3^{a}$ ed., Barcelona, Ariel. [1ªd., 1999.]

Hassler, Gerda (2000), “El Diálogo de la lengua de Juan de Valdés y su redescubrimiento tardío", en Beatrice Bagola (ed.), La lingüística española en la época de los descubrimientos: actas del coloquio en honor del profesor Hans-Josef Niederehe, Hamburg, Buske, p. 59-72.

Jakobson, Roman (1975), Ensayos de lingüística general, Barcelona, Seix Barral.

Lapesa, Rafael (1965), Juan de Valdés: Diálogo de la lengua, $5^{a}$ ed., Zaragoza, Ebro. [Selección, estudio y notas por Rafael Lapesa, $1^{\text {}}$ ed., 1940.]

Lapesa, Rafael (1986), Historia de la lengua española, $9^{a}$ ed., Madrid, Gredos. [1ªd., 1942.]

Lerner, Isaías (2006), "El discurso literario del Diálogo de la lengua de Juan de Valdés”, en Asunción Rallo Gruss y Rafael Malpartida Tirado (eds.), Estudios sobre el diálogo renacentista español "b" antología de la crítica, Málaga, Universidad de Málaga, p. 403-409.

Lope Blanch, Juan M. (1969), Juan de Valdés: Diálogo de la lengua, Madrid, Castalia. [Edición, introducción y notas de Juan M. Lope Blanch.]

Lope Blanch, Juan M. (1986), "La lingüística española del Siglo de Oro”, en A. David Kossoff, Ruth H. Kossoff, Geoffrey Ribbans y José Amor y Vázquez (eds.), Actas del VIII Congreso de la Asociación Internacional de Hispanistas, vol. 1, Madrid, Ediciones Istmo, p. 37-58.

Marcos Sánchez, Mercedes (2006), "Orientaciones en la enseñanza de español como lengua extranjera en la Europa del Siglo XVI”, en José J. Gómez Asencio (ed.), El castellano y su codificación gramatical: de 1492 (A. de Nebrija) a 1611 (John Stanford), vol. 1, Burgos, Fundación Instituto Castellano y Leonés de la Lengua, p. 481-506. 
Martín Peris, Ernesto, Encarna Atienza Cerezo, Maximiano Cortés Moreno, María Vicenta González Argüello, Carmen López Ferrero y Sergi Torner Castells (2008), Diccionario de términos clave de ELE, Madrid, Centro Virtual Cervantes, disponible en http://cvc.cervantes.es/ensenanza/biblioteca_ele/diccio_ele/indice.htm. [Sitio consultado el 10 de abril de 2017.]

Martín Zorraquino, María Antonia y José Portolés Lázaro (1999), "Los marcadores del discurso", en Ignacio Bosque y Violeta Demonte (eds.), Gramática descriptiva de la lengua española, vol. 3, Madrid, Espasa Calpe, p. 4051-4213.

Martínez González, Antonio (1990), "Gramática y enseñanza de la lengua en Nebrija”, en María Ángeles Álvarez Martínez (ed.), Actas del Congreso de la Sociedad Española de Lingüística:XX Aniversario, Madrid, Gredos, p. 611-621.

Martínez González, Antonio (2009), "La Gramática y la enseñanza de la lengua española hasta el siglo XIX”, en Antonio Martínez González (ed.), Historia de las ideas lingüísticas: gramáticos de la España meridional, Frankfurt am Main, Peter Lang, p. 13-64.

Martínez González, Antonio (2017), Temas de historia de la lingüística española, Granada, Universidad de Granada.

Nebrija, Elio Antonio de (1992), Gramática de la lengua castellana, vol. 2, Madrid, Ediciones de Cultura Hispánica. [Edición crítica de Antonio Quilis, $1^{\text {a }}$ ed., 1492.]

Ojeda Álvarez, Diego y Olga Cruz Moya (2004), “'Yo me parto': oralidad, humor, gramática y pragmática, un cóctel lúdico para el aula de ELE”, en María Auxiliadora Castillo Carballo (ed.), Las gramáticas y los diccionarios en la enseñanza del español como segunda lengua: deseo y realidad: actas del XV Congreso Internacional de la Asociación para la enseñanza del Español como Lengua Extranjera (ASELE), Sevilla, Universidad de Sevilla, p. 234-240.

Real Academia Española (2014), Diccionario de la lengua española (DLE), ed. del Tricentenario, $23^{2}$ ed., versión electrónica 23.1., disponible en http://www.rae.es/obras-academicas/diccionarios/diccionario-de-la-lengua-espanola. [Sitio consultado el 12 de abril de 2017.]

Roca Marín, Santiago (2006), "La España de los Austrias: el siglo XVI", Alicante, Biblioteca Virtual Miguel de Cervantes.

Sánchez Pérez, Aquilino (1992), Historia de la enseñanza del español como lengua extranjera, Madrid, SGEL.

Sevilla Muñoz, Julia y María Sardelli (2007), "Las concordancias paremiológicas del Diálogo de la lengua de Juan de Valdés y el Vocabulario de refranes y frases proverbiales de Gonzalo Correas", Criticón, n 99, p. 67-91. 